\title{
PENINGKATKAN AKTIVITAS BELAJAR BAHASA INDONESIA MELALUI MODEL DISCOVERY LEARNING PADA SISWA KELAS VII.1 SMPN 3 KOTO BARU
}

\author{
RINA NOVIANA \\ SMPN 3 Koto Baru, Dharmasraya \\ rinan3737@gmail.com
}

\begin{abstract}
This study aims to improve Indonesian language learning activities through the application of discovery learning models to class VII.1 students of SMPN 3 Koto Baru. Classroom action research was carried out for two cycles, with each cycle holding two meetings. Each meeting is held by applying the discovery learning model. As a data collection tool is the result of observation of student learning activities in cycle 1 and cycle 2. The results of research obtained on student learning activities at the initial observation of 68\% categories (less active), increased $80 \%$ categories (active) in the first cycle, and increased again $85 \%$ (active) category in cycle II. Learning activities of students learning Indonesian experience an improvement from the first cycle to the second cycle, this shows that the discovery learning model can be used as an alternative learning to improve student learning activities.
\end{abstract}

Keywords: learning activities, discovery learning models, Indonesian

\begin{abstract}
Abstrak: Penelitian ini bertujuan meningkatkan aktivitas belajar Bahasa Indonesia melalui penerapan model discovery learning pada siswa kelas VII.1 SMPN 3 Koto Baru . Penelitian tindakan kelas dilaksanakan selama dua siklus dengan setiap siklus diadakan dua kali pertemuan. Tiap pertemuan dilaksanakan dengan penerapan model discovery learning. Sebagai alat pengumpul data adalah hasil observasi aktivitas belajar siswa pada siklus 1 dan siklus 2 . Hasil penelitian yang diperoleh mengenai aktivitas belajar siswa pada pengamatan awal dari 68\% kategori (kurang aktif), meningkat 80\% kategori (aktif) pada siklus I, dan meningkat lagi $85 \%$ kategori (aktif) pada siklus II . Aktivitas belajar siswa belajar Bahasa Indonesia mengalami perbaikan dari siklus pertama ke siklus kedua, hal ini menunjukkan bahwa model discovery learning dapat dijadikan sebagai pembelajaran alternatif untuk meningkatkan aktivitas belajar siswa.
\end{abstract}

Kata kunci : aktivitas belajar,model discovery learning, bahasa Indonesia

\section{A. Pendahuluan}

Bahasa merupakan suatu alat komunikasi atau alat untuk berinteraksi, dalam arti untuk menyampaikan pikiran, gagasan, konsep atau perasaan. Keterampilan berbahasa sangat penting bagi siswa untuk berkomunikasi dengan baik. Keterampilan berbahasa mencakup empat segi, yaitu keterampilan menyimak, keterampilan berbicara, keterampilan membaca, dan keterampilan menulis (Tarigan, 2008:1). Dari keempat keterampilan tersebut saling berhubungan, sebelum pada tahap menulis dibutuhkan kegiatan menyimak dan membaca. Melalui menyimak dan membaca siswa tidak hanya memperoleh ide atau informasi untuk tulisannya tetapi juga mendapatkan inspirasi untuk menulis dengan struktur yang baik. Keterampilan berbicara dan menulis suatu keterampilan berbahasa yang bersifat aktif, pesan yang disampaikan dalam tulisan dapat siswa dapatkan dari hasil berbicara. Maka dari keempat 
keterampilan tersebut siswa dapat dengan mudah menuangkan ide atau gagasannya dalam bentuk tulisan.

Keterampilan menulis memiliki peranan penting dalam kehidupan manusia. Keterampilan ini merupakan kegiatan yang produktif dan ekspresif sehingga keterampilan ini tidak datang dengan sendirinya tetapi membutuhkan latihan dan kebiasaan yang berkesinambungan. Keterampilan menulis dikatakan produktif karena keterampilan tersebut terbentuk dari proses terintegrasinya apa yang telah didengar, dibicarakan dan dibaca, kemudian di ekspresikan kembali dalam bentuk tulisan. Seseorang yang memiliki keterampilan menulis dapat mengungkapkan pikiran dan gagasannya untuk mencapai maksud dan tujuan tertentu. Gagasan itu dapat berupa fakta, pengalaman, pengamatan, penelitian, pemikiran atau analisis suatu masalah. Salah satu keterampilan menulis yang terdapat pada kurikulum 2013 revisi 2016 di kelas VII Sekolah Menengah Pertama (SMP) adalah keterampilan menulis teks prosedur.

As'Adah (2016) berdasarkan prinsip pembelajaran Bahasa Indonesia dalam Kurikulum 2013, siswa dituntut mampu memproduksi atau menulis teks dengan baik dan benar. Sejalan dengan hal tersebut, arah pembelajaran keterampilan menulis di SMP berdasarkan Kurikulum 2013 lebih dititikberatkan pada tingkat kreatifitas siswa dalam mengembangkan ide dan gagasannya. Teks prosedur merupakan suatu langkahlangkah dan tujuan yang harus diikuti agar suatu pekerjaan dapat dilakukan. Teks prosedur memiliki manfaat yang besar dalam kehidupan. Teks prosedur membantu mengetahui cara-cara melakukan aktifitas tertentu dan kebiasaan hidup yang benar. Selain itu, membantu dalam menggunakan alat dengan benar tanpa membahayakan diri dan tanpa merusak alat itu sendiri. Untuk mencapai tujuan yang tepat teks prosedur harus disusun sesuai dengan urutan yang benar. Karena langkah-langkah dalam menyusun teks prosedur tidak dapat dibalik-balik untuk mencapai tujuan tersebut.

Pradana (2013) mengatakan bahwa pelajaran menulis teks prosedur menjadi penting karena setiap peserta didik mampu memahami dan mengutarakan idenya. Apabila ide tersebut diutarakan secara sistematis dan terperinci pelajaran bahasa Indonesia di sekolah-sekolah yang memasukkan teks prosedur sebagai salah satu materi yang dianggap penting dapat dipahami oleh siswa. Lebih lanjut Harsiati, dkk (2017:88) juga menyatakan, "Teks prosedur menjelaskan kegiatan yang harus dilakukan agar pembaca/pemirsa dapat secara tepat dan akurat mengikuti sebuah proses membuat sesuatu, melakukan suatu pekerjaan, atau menggunakan suatu alat". Tujuan komunikatif teks prosedur adalah memberikan petunjuk atau cara melakukan sesuatu melalui serangkaian tindakan atau langkah-langkah (Kemendikbud,2013 : 84). Teks prosedur sangat perlu dikuasai oleh siswa karena dalam pembelajaran teks prosedur merupakan suatu bentuk teks yang berisi langkah-langkah atau tahapan tahapan yang herus ditempuh untuk melakukan sesuatu agar dapat dengan mudah dan benar dalam mengerjakannya. Ada banyak sekali kegiatan-kegiatan yang harus mengikuti prosedur agar kegiatan tersebut berjalan lancar dan tanpa hambatan yang akan membuat kegiatan tersebut menjadi salah maupun gagal.

Berdasarkan fakta dan data yang diperoleh dari observasi awal yang dilakukan oleh peneliti di SMP Negeri 3 Koto Baru menunjukkan bahwa aktivitas belajar siswa kelas VII.1 masih cukup rendah. Berdasarkan jumlah siswa kelas VII.1 sebanyak 21 orang, jumlah siswa dengan aktivitas kategori aktif hanya berjumlah 10 orang sedangkan kategori kurang aktif berjumlah 11 orang. Secara Klasikal rata-rata aktivitas belajar siswa kelas VII.1 masih pada 68\% kategori kurang aktif. Dilihat 
dari kondisi siswa dalam proses belajar mengajar, peneliti mendapat gambaran bahwa selama pembelajaran berlangsung siswa kurang bersemangat untuk belajar, kurang adanya kerja sama kelompok untuk bertukar pikiran dan menyelesaikan suatu permasalahan serta kurang adanya variasi penggunaan model pembelajaran sehingga menimbulkan suatu kebosanan. Oleh karena itu setiap pembelajaran berlangsung hendaknya melibatkan seluruh siswa sehingga siswa dapat berpartisipasi secara aktif dengan materi yang sedang dipelajari.

Berangkat dari kenyataan atau kondisi di lapangan dan permasalahan yang ditemui, mengindikasikan bahwa proses pembelajaran perlu diperbaiki. Siswa harus mendapatkan pengalaman belajar, yang lebih baik dan memotivasi. Salah satu upaya untuk menciptakan pembelajaran yang mampu melibatkan siswa untuk membangun aktivitas dan hasil belajar dibutuhkan sebuah alternatif model pembelajaran. Upaya membantu siswa dalam meningkatkan aktivitas belajar, salah satu alternatif yang dipilih dalam hal ini adalah dengan memberikan model pembelajaran Discovery Learning . diharapkan dapat meningkatkan aktivitas belajar menjadi lebih baik dibandingkan pembelajaran sebelumnya.

Rumusan Masalah dari penelitian ini adalah "Apakah Melalui Penerapan Model pembelajaran Discovery Learning Dapat Meningkatkan Aktivitas Belajar Bahasa Indonesia Pada Siswa Kelas VII.1 SMP Negeri 3 Koto Baru?" Hipotesis tindakan penelitian ini adalah "meningkatnya aktivitas belajar Bahasa Indonesia melalui penerapan model pembelajaran Discovery Learning pada siswa kelas VII.1 SMP Negeri 3 Koto Baru." Tujuan yang diharapkan dalam penelitian ini adalah untuk mengetahui apakah melalui penerapan model pembelajaran Discovery Learning dapat meningkatkan aktivitas belajar Bahasa Indonesia pada siswa kelas VII.1 SMP Negeri 3 Koto Baru.

\section{B. Metodologi Penelitian}

Jenis penelitian ini adalah penelitian tindakan kelas yang dilakukan guru mata pelajaran Bahasa Indonesia di kelas VII.1 SMPN 3 Koto Baru. Guru adalah peneliti yang akan memperbaiki proses pembelajarannya di kelas. Subyek penelitian adalah kelas VII.1 SMPN 3 Koto baru yang berjumlah 21 orang siswa, terdiri dari 9 lakilaki dan 12 orang perempuan. Penelitian ini diadakan pada semester ganjil Tahun Pelajaran 2019/2020. Objek penelitian tindakan kelas ini adalah pembelajaran Bahasa Indonesia dengan materi "Teks Prosedur" di kelas VII.1 Semester Ganjil SMPN 3 Koto Baru Tahun Pelajaran 2019/2020 , untuk melihat peningkatan aktivitas belajar siswa selama proses belajar mengajar berlangsung melalui penerapan Model pembelajaran Discovery Learning. Teknik Pengumpulan data pada penelitian ini, kolaborator mengamati situasi dan kondisi siswa selama proses belajar mengajar berlangsung. Pada pengamatan, observer melakukan checlist untuk mengetahui perkembangan aktivitas siswa dalam mengikuti pembelajaran. Menggunakan Teknik Analisis deskriptif komparatif tabulasi, dimana data yang didapatkan dari hasil pengisian lembar pengamatan dirata-ratakan dan dibandingkan. Untuk pengolahan disajikan dalam bentuk tabel dan diagram batang dan diinterpretasikan. Indikator keberhasilan tindakan dapat dilihat jika terdapat peningkatan aktifitas belajar secara kualitatif dan kuantitatif. Aktifitas belajar siswa berada pada kategori "aktif", jika nilai $\geq 75 \%$, yang dapat dilihat dari aktifitas: 1) Memusatkan perhatian pada materi pelajaran teks prosedur dengan serius, 2) aktif dalam pernyataan/ identifikasi masalah tentang materi teks prosedur, 3) berinteraksi dengan siswa lain dalam kelompok 
mengumpulkan data/informasi tentang materi teks prosedur, 4) aktif dalam pengolahan data teks prosedur, 5) menyusun laporan menulis teks prosedur dengan baik, 6) berpartisipasi aktif dalam presentasi kelompok.

\section{Hasil dan Pembahasan}

Deskripsi Kondisi Awal

Aktivitas belajar Bahasa Indonesia siswa kelas VII.1 SMPN 3 Koto Baru pada kondisi awal (Pra Siklus) dapat dilihat dalam tabel 1 dibawah ini:

Tabel 1. Aktivitas Belajar Bahasa Indonesia pada siswa Kelas VII.1 SMPN 3 Koto Baru pada Kondisi Awal

\begin{tabular}{|c|c|c|c|c|c|c|c|c|c|c|c|}
\hline \multirow{3}{*}{$\begin{array}{l}\mathbf{N} \\
\mathbf{O}\end{array}$} & \multirow{3}{*}{ NAMA SISWA } & $\mathrm{L}$ & \multirow{2}{*}{\multicolumn{8}{|c|}{$\begin{array}{l}\text { AKTIVITAS BELAJAR SISWA } \\
\text { PADA } \\
\text { PRASIKLUS }\end{array}$}} & \multirow{3}{*}{ KATEGORI } \\
\hline & & I & & & & & & & & & \\
\hline & & $\mathrm{P}$ & 1 & 2 & 3 & 4 & 5 & 6 & $\begin{array}{c}\mathbf{J m} \\
\mathbf{l}\end{array}$ & $\%$ & \\
\hline 1 & Aiken Betranogi & $\mathrm{L}$ & 1 & 1 & 1 & 1 & 1 & & 5 & 83 & AKTIF \\
\hline 2 & Aruni Agustin & $\mathrm{P}$ & & & 1 & 1 & & 1 & 3 & 50 & $\begin{array}{c}\text { KURANG } \\
\text { AKTIF }\end{array}$ \\
\hline 3 & Aulia Renita & $\mathrm{P}$ & 1 & 1 & 1 & 1 & 1 & & 5 & 83 & AKTIF \\
\hline 4 & Dina Novia & $\mathrm{P}$ & 1 & & 1 & & & 1 & 3 & 50 & $\begin{array}{c}\text { KURANG } \\
\text { AKTIF }\end{array}$ \\
\hline 5 & Giska & $\mathrm{P}$ & 1 & 1 & & 1 & 1 & 1 & 5 & 83 & AKTIF \\
\hline 6 & Keysha Amalia & $\mathrm{P}$ & 1 & 1 & 1 & & & 1 & 4 & 67 & $\begin{array}{c}\text { KURANG } \\
\text { AKTIF }\end{array}$ \\
\hline 7 & Muhammad Hanif & $\mathrm{L}$ & & & 1 & & 1 & 1 & 3 & 50 & $\begin{array}{c}\text { KURANG } \\
\text { AKTIF }\end{array}$ \\
\hline 8 & Muzhafal & $\mathrm{L}$ & 1 & & & 1 & 1 & & 3 & 50 & $\begin{array}{c}\text { KURANG } \\
\text { AKTIF }\end{array}$ \\
\hline 9 & Nayla Nania Fazzahra & $\mathrm{P}$ & 1 & & 1 & 1 & 1 & 1 & 5 & 83 & AKTIF \\
\hline 10 & Panewar & $\mathrm{P}$ & & & 1 & 1 & & 1 & 3 & 50 & $\begin{array}{c}\text { KURANG } \\
\text { AKTIF }\end{array}$ \\
\hline 11 & Rafli Ahmad & $\mathrm{L}$ & 1 & & 1 & & 1 & & 3 & 50 & $\begin{array}{c}\text { KURANG } \\
\text { AKTIF }\end{array}$ \\
\hline 12 & Rahmad Kurnia & $\mathrm{L}$ & 1 & 1 & 1 & & 1 & 1 & 5 & 83 & AKTIF \\
\hline 13 & Safira Noviana & $\mathrm{P}$ & 1 & & 1 & 1 & 1 & 1 & 5 & 83 & AKTIF \\
\hline 14 & Suci Laura Alsi & $\mathrm{P}$ & 1 & 1 & & 1 & 1 & 1 & 5 & 83 & AKTIF \\
\hline 15 & Tasurun Nazirin & $\mathrm{L}$ & & 1 & 1 & 1 & & & 3 & 50 & $\begin{array}{c}\text { KURANG } \\
\text { AKTIF }\end{array}$ \\
\hline 16 & Umair & $\mathrm{L}$ & 1 & 1 & 1 & 1 & 1 & 1 & 6 & 100 & AKTIF \\
\hline 17 & Vania Widiandika & $\mathrm{P}$ & 1 & 1 & 1 & & 1 & 1 & 5 & 83 & AKTIF \\
\hline 18 & Wesi Chania & $\mathrm{P}$ & 1 & 1 & 1 & 1 & & & 4 & 67 & $\begin{array}{c}\text { KURANG } \\
\text { AKTIF }\end{array}$ \\
\hline 19 & Widia Vanesha & $\mathrm{P}$ & 1 & 1 & 1 & 1 & & 1 & 5 & 83 & AKTIF \\
\hline 20 & Yengki Wiranda & $\mathrm{L}$ & & & 1 & & 1 & 1 & 3 & 50 & $\begin{array}{c}\text { KURANG } \\
\text { AKTIF }\end{array}$ \\
\hline
\end{tabular}




\begin{tabular}{|c|c|c|c|c|c|c|c|c|c|c|c|}
\hline 21 & Yogi Fernando & $\mathrm{L}$ & & & 1 & 1 & 1 & & 3 & 50 & $\begin{array}{c}\text { KURANG } \\
\text { AKTIF }\end{array}$ \\
\hline & Jumlah & & $\begin{array}{l}1 \\
5\end{array}$ & $\begin{array}{l}1 \\
1\end{array}$ & $\begin{array}{l}1 \\
8\end{array}$ & $\begin{array}{l}1 \\
4\end{array}$ & $\begin{array}{l}1 \\
4\end{array}$ & $\begin{array}{l}1 \\
4\end{array}$ & 86 & 1,433 & \\
\hline & Rerata & & $\begin{array}{l}5 \\
6\end{array}$ & $\begin{array}{l}4 \\
1\end{array}$ & $\begin{array}{l}6 \\
7\end{array}$ & $\begin{array}{l}5 \\
2\end{array}$ & $\begin{array}{l}5 \\
2\end{array}$ & $\begin{array}{l}5 \\
2\end{array}$ & 53 & 68 & $\begin{array}{c}\text { KURANG } \\
\text { AKTIF }\end{array}$ \\
\hline
\end{tabular}

Bila digambarkan dengan menggunakan Histogram, maka aktivitas belajar bahasa Indonesia pada kondisi awal (Pra siklus) yaitu sebagai berikut:

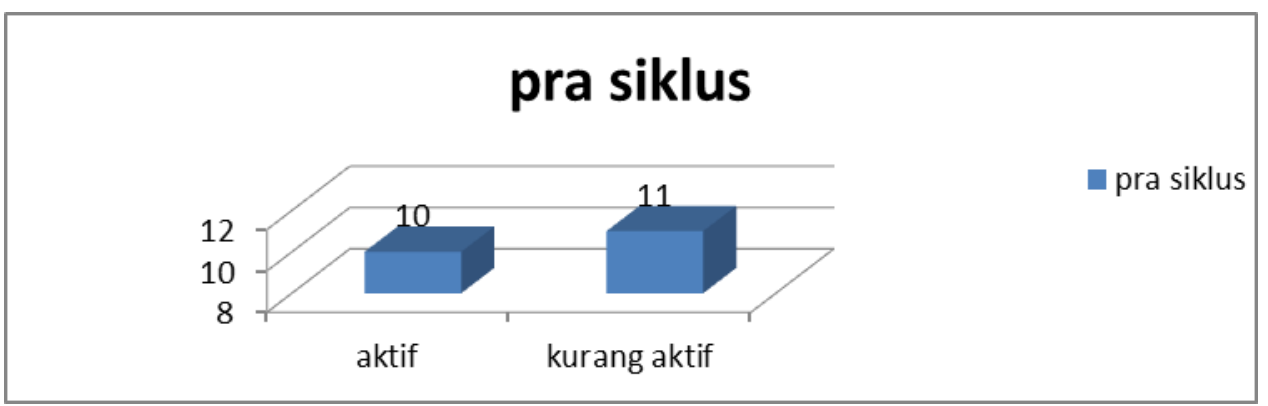

Histogram 1. Aktivitas Belajar Bahasa Indonesia Siswa Kelas VII.1 SMPN 3 Koto Baru padaKondisi Awal (Pra Siklus).

Setelah diketahui bahwa di Kelas VII.1 masih terdapat permasalahan terkait aktivitas belajar siswa yang belum mencapai kategori Aktif, Peneliti menerapkan tindakan untuk materi pada KD berikutnya, yaitu KD. 3.5 Mengidentifikasi teks prosedur tentang cara melakukan sesuatu dan cara membuat (cara memainkan alat musik/tarian daerah, cara membuat kuliner khas daerah, dll.) dari berbagai sumber yang dibaca dan didengar.

\section{Aktivitas Belajar Siklus I}

Aktivitas belajar siswa belajar Bahasa Indonesia pada siklus I melalui penerapan Model Pembelajaran discovery learning pada siswa Kelas VII.1 SMPN 3 Koto Baru, telah memperlihatkan peningkatan (lihat lampiran 4 dan 5). Bila aktivitas belajar siklus I pada pertemuan I dan II dirata-ratakan dapat dilihat dalam tabel berikut :

Tabel 2. Peningkatan aktivitas belajar siswa dengan Model Discovery Learning pada siklus I di kelas VII.1 SMPN 3 Koto Baru

\begin{tabular}{|c|l|c|c|c|c|}
\hline \multirow{2}{*}{ NO } & \multirow{2}{*}{ NAMA SISWA } & \multicolumn{3}{|c|}{ AKTIVITAS BELAJAR SISWA PADA SIKLUS I } \\
\cline { 3 - 6 } & $\begin{array}{c}\text { PERTEMUAN } \\
\mathbf{1}\end{array}$ & $\begin{array}{c}\text { PERTEMUAN } \\
\mathbf{2}\end{array}$ & $\begin{array}{c}\text { Rata- } \\
\text { Rata }\end{array}$ & KATEGORI \\
\cline { 3 - 6 } & $\%$ & $\%$ & 83 & AKTIF \\
\hline 1 & Aiken Betranogi & 83 & 83 & 50 & $\begin{array}{c}\text { KURANG } \\
\text { AKTIF }\end{array}$ \\
\hline 2 & Aruni Agustin & 50 & 50 & 83 & AKTIF \\
\hline 3 & Aulia Renita & 83 & 83 & 83 & AKTIF \\
\hline 4 & Dina Novia & 83 & 83 & 100 & AKTIF \\
\hline 5 & Giska & 100 & 100 & 63 & AKTIF \\
\hline 6 & Keysha Amalia & 83 & 67 & 67 & KURANG \\
\hline 7 & Muhammad Hanif & 67 & $67 F$ \\
\hline \hline
\end{tabular}

16 Lembaga Penelitian dan Penerbitan Hasil Penelitian Ensiklopedia 


\begin{tabular}{|c|l|c|c|c|c|}
8 & Muzhafal & 50 & 50 & 50 & $\begin{array}{c}\text { KURANG } \\
\text { AKTIF }\end{array}$ \\
\hline 9 & $\begin{array}{l}\text { Nayla Nania } \\
\text { Fazzahra }\end{array}$ & 100 & 100 & 100 & AKTIF \\
\hline 10 & Panewar & 83 & 83 & 83 & AKTIF \\
\cline { 1 - 2 } 11 & Rafli Ahmad & 67 & 67 & 67 & $\begin{array}{c}\text { KURANG } \\
\text { AKTIF }\end{array}$ \\
\hline 12 & Rahmad Kurnia & 83 & 83 & 83 & AKTIF \\
\hline 13 & Safira Noviana & 83 & 83 & 83 & AKTIF \\
\hline 14 & Suci Laura Alsi & 83 & 83 & 83 & AKTIF \\
\hline 15 & Tasurun Nazirin & 67 & 67 & 67 & KURANG \\
\cline { 1 - 2 } 16 & Umair & 100 & 100 & 100 & AKTIF \\
\hline 17 & Vania Widiandika & 100 & 100 & 100 & AKTIF \\
\hline 18 & Wesi Chania & 67 & 83 & 75 & AKTIF \\
\hline 19 & Widia Vanesha & 83 & 83 & 83 & AKTIF \\
\hline 20 & Yengki Wiranda & 83 & 83 & 83 & AKTIF \\
\hline 21 & Yogi Fernando & 50 & 83 & 66,5 & \\
\hline & Jumlah & 1.650 & 1.700 & 1675 & AKTIF \\
\hline & Rerata & $\mathbf{7 9}$ & $\mathbf{8 1}$ & $\mathbf{8 0}$ & A \\
\cline { 1 - 2 }
\end{tabular}

Pada siklus I terjadi peningkatan jumlah siswa yang aktif belajar bahasa Indonesia melalui penggunaan model discovery learning menjadi 15 orang bila dibandingkan pada pra siklus berjumlah 10 orang, berarti meningkat 5 poin.

\section{Aktivitas Belajar Siklus II}

Aktivitas belajar siswa belajar Bahasa Indonesia pada siklus I melalui penerapan model pembelajaran discovery learning pada siswa kelas VII.1 SMPN 3 Koto Baru, telah memperlihatkan peningkatan (lihat lampiran 4 dan 5). Bila aktivitas belajar siklus II pada pertemuan I dan II dirata-ratakan dapat dilihat dalam tabel berikut :

Tabel 3. Peningkatan aktivitas belajar siswa dengan Model Discovery Learning pada siklus II di kelas VII.1 SMPN 3 Koto Baru

\begin{tabular}{|c|c|c|c|c|c|}
\hline \multirow{3}{*}{ NO } & \multirow{3}{*}{ NAMA SISWA } & \multicolumn{4}{|c|}{ AKTIVITAS BELAJAR SISWA PADA SIKLUS II } \\
\hline & & \multirow{2}{*}{$\begin{array}{c}\text { PERTEMUA } \\
\text { N } 1 \\
\%\end{array}$} & $\begin{array}{c}\text { PERTEMUA } \\
\mathbf{N} \quad 2 \\
\end{array}$ & \multirow{2}{*}{$\begin{array}{l}\text { Rata- } \\
\text { Rata }\end{array}$} & \multirow[t]{2}{*}{ KATEGORI } \\
\hline & & & $\%$ & & \\
\hline 1 & Aiken Betranogi & 83 & 83 & 83 & AKTIF \\
\hline 2 & Aruni Agustin & 67 & 83 & 75 & AKTIF \\
\hline 3 & Aulia Renita & 83 & 83 & 83 & AKTIF \\
\hline 4 & Dina Novia & 83 & 83 & 83 & AKTIF \\
\hline 5 & Giska & 100 & 100 & 100 & AKTIF \\
\hline 6 & Keysha Amalia & 83 & 100 & 92 & AKTIF \\
\hline 7 & Muhammad Hanif & 83 & 83 & 83 & AKTIF \\
\hline 8 & Muzhafal & 50 & 67 & 59 & $\begin{array}{c}\text { KURANG } \\
\text { AKTIF }\end{array}$ \\
\hline
\end{tabular}




\begin{tabular}{|c|c|c|c|c|c|}
\hline 9 & $\begin{array}{l}\text { Nayla Nania } \\
\text { Fazzahra }\end{array}$ & 100 & 100 & 100 & AKTIF \\
\hline 10 & Panewar & 83 & 83 & 83 & AKTIF \\
\hline 11 & Rafli Ahmad & 67 & 67 & 67 & $\begin{array}{c}\text { KURANG } \\
\text { AKTIF }\end{array}$ \\
\hline 12 & Rahmad Kurnia & 83 & 83 & 83 & AKTIF \\
\hline 13 & Safira Noviana & 83 & 83 & 83 & AKTIF \\
\hline 14 & Suci Laura Alsi & 83 & 83 & 83 & AKTIF \\
\hline 15 & Tasurun Nazirin & 67 & 83 & 75 & AKTIF \\
\hline 16 & Umair & 100 & 100 & 100 & AKTIF \\
\hline 17 & Vania Widiandika & 100 & 100 & 100 & AKTIF \\
\hline 18 & Wesi Chania & 83 & 83 & 83 & AKTIF \\
\hline 19 & Widia Vanesha & 83 & 83 & 83 & AKTIF \\
\hline 20 & Yengki Wiranda & 83 & 83 & 83 & AKTIF \\
\hline 21 & Yogi Fernando & 83 & 83 & 83 & AKTIF \\
\hline & Jumlah & 1.733 & 1.800 & 1766,5 & \multirow{2}{*}{ AKTIF } \\
\hline & Rerata & 83 & 86 & 85 & \\
\hline
\end{tabular}

\section{Persentase Aktivitas siswa}

Persentase aktivitas siswa belajar bahasa Indonesia pada siklus I mengalami peningkatan. Pada pertemuan 1 rata-rata $79 \%$ meningkat pada pertemuan 2 menjadi $81 \%$ dengan rata-rata $80 \%$ kategori Aktif. Pada siklus II pertemuan I rata-rata $83 \%$ meningkat pada pertemuan 2 menjadi $86 \%$ dengan rata-rata $85 \%$ Kategori Aktif

\section{Pembahasan hasil Siklus I}

Pada siklus I guru mempersiapkan materi pelajaran dengan menggunakan model pembelajaran discovery learning. Setelah guru menjelaskan tujuan pembelajaran kemudian melanjutkan dengan arahan-arahan kegiatan pembelajaran, guru menayangkan cakupan materi pelajaran menggunakan MS. Power Point. Siswa melakukan studi literatur sesuai dengan indikator pencapaian kompetensi, dan mengerjakan Lembar Kerja siswa. Siswa dibagi menjadi 5 kelompok dengan jumlah anggota 4 orang dalam 1 kelompok, sesuai dengan deret bangku dikelas. Tahap yang akan dilakukan oleh siswa yaitu : Stimulation (stimulasi/ pemberian rangsangan), Problem statement (pernyataan/ identifikasi masalah), Data Collection (Pengumpulan Data), Data Processing (pengolahan Data), dan Verification (Pembuktian).

Selama pelaksanakan siklus I yang dilaksanakan 2 kali pertemuan. Dari hasil Observasi didapat data aktivitas belajar siswa belajar bahasa Indonesia melalui penerapan model discovery learning seperti yang tercantum dalam tabel dibawah ini:

Tabel 4. Aktivitas belajar bahasa Indonesia dengan model discovery learning pada siklus I siswa kelas VII.1 SMPN 3 Koto Baru

\begin{tabular}{|c|c|c|c|}
\hline KETERANGAN & PERTEMUAN 1 & PERTEMUAN 2 & JUMLAH \\
\hline Aktif & 14 orang & 16 orang & 2 orang \\
\hline
\end{tabular}




\begin{tabular}{|c|c|c|c|}
\hline & & & (meningkat) \\
\hline Kurang aktif & 7 orang & 5 orang & 2 orang (menurun) \\
\hline
\end{tabular}

Dari tabel diatas dapat dilihat jumlah siswa yag aktif dalam belajar bahasa Indonesia pada siklus I dengan model discovery learning pada pertemuan 1 berjumlah 14 orang meningkat menjadi 16 orang pada pertemuan 2 , berarti meningkat 2 orang. Sedangkan siswa yang kurang aktif dari 7 orang pada pertemuan 1 turun menjadi 5 orang pada pertemuan 2. Bila digambarkan dengan menggunakan histogram seperti dibawah ini:

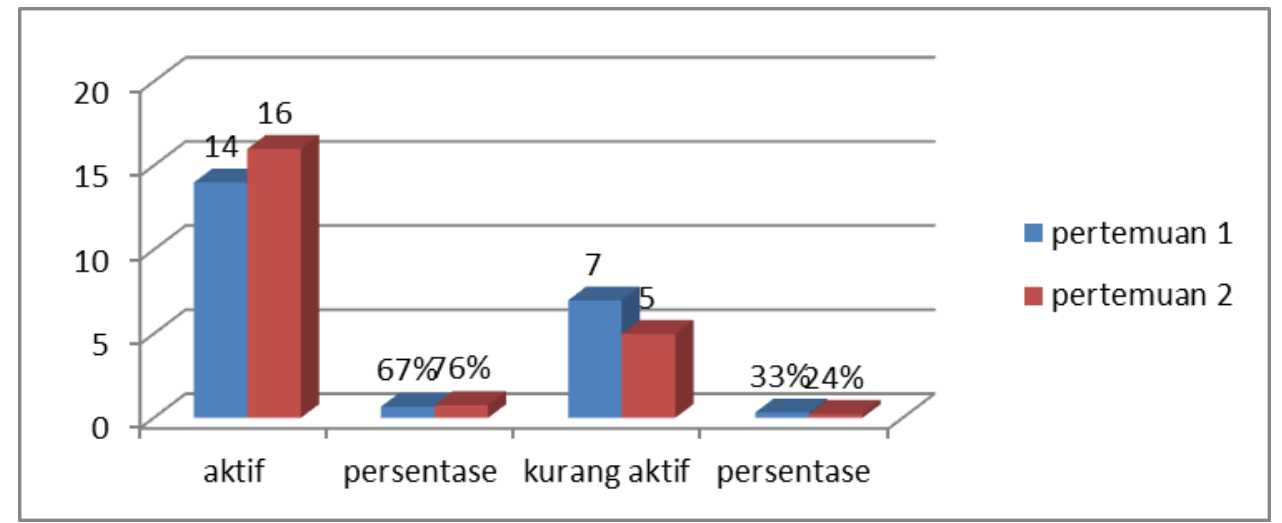

Histogram 2. Persentase Aktivitas belajar bahasa Indonesia dengan model Discovery learning pada siklus I siswa kelas VII.1 SMPN 3 Koto Baru

Dapat dijelaskan bahwa persentase siswa yang aktif pada pertemuan 1 yaitu $67 \%$ dengan 14 orang siswa, pada pertemuan 2 yaitu $76 \%$ dengan 16 jumlah orang siswa.

\section{Pembahasan siklus II}

Pada siklus II guru mempersiapkan materi pelajaran dengan menggunakan model pembelajaran discovery learning. Setelah guru menjelaskan tujuan pembelajaran kemudian melanjutkan dengan arahan-arahan kegiatan pembelajaran, guru menayangkan cakupan materi pelajaran menggunakan MS. Power Point. Siswa melakukan studi literatur sesuai dengan indikator pencapaian kompetensi, dan mengerjakan Lembar Kerja siswa. Siswa dibagi menjadi 5 kelompok dengan jumlah anggota 4 orang dalam 1 kelompok, formasi anggota kelompok dirubah dengan memperhatikan kemampuan siswa yang lebih, sedang dan kurang. Guru juga memberikan motivasi agar semangat siswa lebih terpacu dalam diskusi kelompok, kelompok yang lebih dahulu dalam menyiapkan tugas kelompok maka akan mendapat nilai tertinggi dan bonus bila mengerjakan tugas tepat waktu. Tahap yang akan dilakukan oleh siswa yaitu : Stimulation (stimulasi/ pemberian rangsangan), Problem statement (pernyataan/ identifikasi masalah), Data Collection (Pengumpulan Data), Data Processing (pengolahan Data), Verification (Pembuktian).

Setelah dilaksanakan siklus II, yang dilaksanakan 2 kali pertemuan, didapat data hasil observasi aktivitas siswa belajar bahasa Indonesia seperti yan tercantum dalam tabel berikut ini:

Tabel 5. Aktivitas belajar bahasa Indonesia dengan model discovery learning pada siklus II siswa kelas VII.1 SMPN 3 Koto Baru

\begin{tabular}{l|l|l|l} 
KETERANGAN & PERTEMUAN 1 & PERTEMUAN 2 & JUMLAH \\
\hline
\end{tabular}




\begin{tabular}{|c|c|c|l|}
\hline Aktif & 17 siswa & 19 siswa & $\begin{array}{l}2 \text { siswa } \\
\text { (meningkat) }\end{array}$ \\
\hline Kurang aktif & 4 siswa & 2 siswa & 2 siswa (menurun) \\
\hline
\end{tabular}

Dari tabel diatas dapat dilihat jumlah siswa yag aktif dalam belajar bahasa Indonesia pada siklus II dengan model discovery learning pada pertemuan 1 berjumlah 17 orang meningkat menjadi 19 orang pada pertemuan 2, berarti meningkat 2 orang. Sedangkan siswa yang kurang aktif dari 4 orang pada pertemuan 1 turun menjadi 2 orang pada pertemuan 2. Bila digambarkan dengan menggunakan histogram seperti dibawah ini:

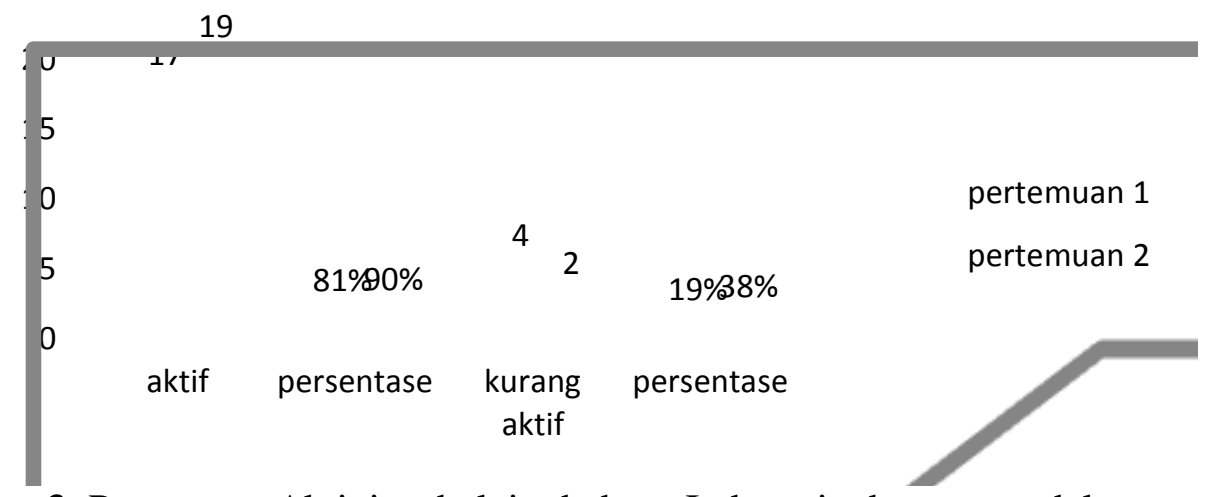

Histogram 3. Persentase Aktivitas belajar bahasa Indonesia dengan model

Discovery learning pada siklus II siswa kelas VII.1 SMPN 3 Koto Baru Dapat dijelaskan bahwa pada siklus II persentase siswa yang aktif pada pertemuan 1 yaitu $81 \%$ dengan 17 orang siswa, pada pertemuan 2 yaitu $90 \%$ dengan jumlah 19 orang siswa.

\section{Pembahasan persentase Peningkatan aktivitas Pra Siklus, siklus I dan Siklus II}

Persentase peningkatan rata-rata aktivitas belajar siswa pra siklus, siklus I dan siklus II seperti dalam tabel dibawah ini:

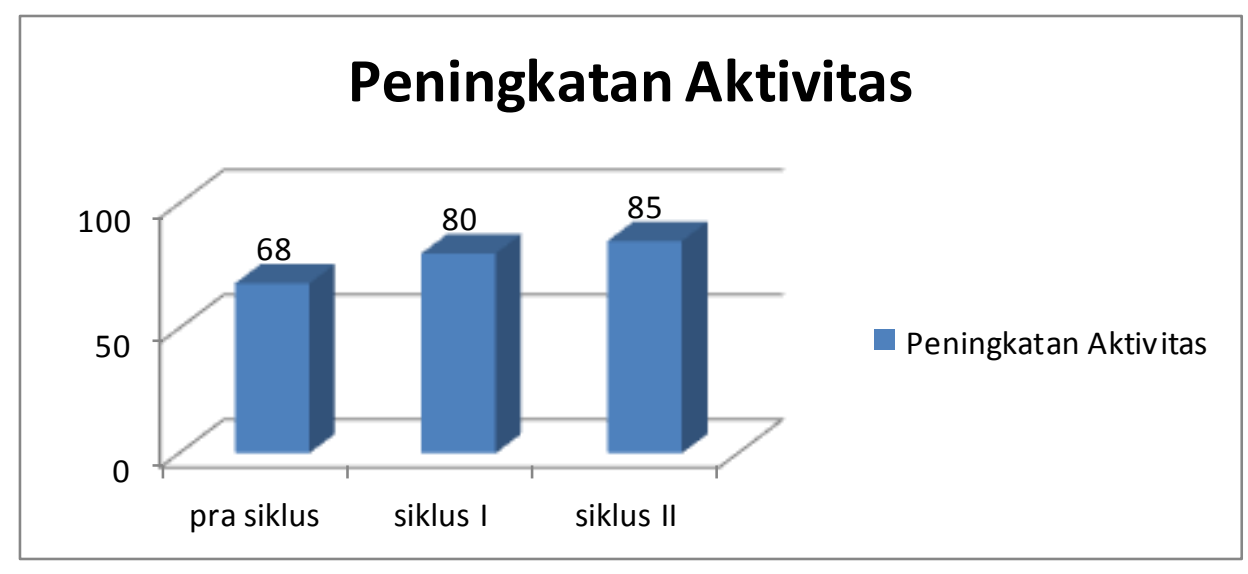

Histogram 4. Persentase Peningkatan Aktivitas Belajar Bahasa Indonesia dengan Model Discovery Learning pada Pra Siklsu, Siklus I dan Siklus II Siswa Kelas VII.1 SMPN 3 Koto Baru

Dari data tabel diatas dapat dilihat pada pra siklus persentase rata-rata aktivitas belajar Bahasa Indonesia yaitu $68 \%$ meningkat menjadi $80 \%$ pada siklus I dan meningkat lagi menjadi $85 \%$ pada siklus II berarti telah terjadi peningkatan aktivitas belajar bahasa 
Indonesia melalui penerapan model discovery learning sehingga siklus dalam penelitian ini tidak dilanjutkan lagi.

\section{Penutup}

Berdasarkan temuan hasil penelitian, pada penelitian tindakan kelas dapat ditarik kesimpulan : "Jika pada siswa kelas VII.1 SMPN 3 Koto Baru Dharmasraya TP 2019/2020 dilakukan proses pembelajaran dengan menggunakan model pembelajaran discovery pada mata pelajaran Bahasa Indonesia, maka akan terjadi peningkatan persentase aktivitas belajar dari pra siklus 68\% kategori kurang aktif, meningkat menjadi $80 \%$ kategori aktif pada siklus I, dan meningkat lagi menjadi $85 \%$ aktif pada siklus II ". Untuk menyempurnakan hasil yang diperoleh dalam penelitian ini maka diajukan saran sebagai berikut : 1) dalam penggunaan model discovery learning efesiensi waktu harus dirancang dengan baik agar tidak banyak waktu yang terbuang dalam melaksanakan proses pembelajaran, 2) bagi siswa yang terlibat dalam penelitian ini agar tetap menanamkan sikap positif dalam pembelajaran bahasa Indonesia yaitu kreativ, inovatif, menjalin kerjasama yang baik, dan bersemangat dalam belajar, 3) diharapkan rekan guru terus berupaya profesionalismenya dengan melahirkan inovasi dan kreasi berbagai model/metode dan media pembelajaran pada mata pelajaran yang diampunya.

\section{Daftar Pustaka}

Abidin, Yunus. 2012. Pembelajaran Bahasa Berbasis Pendidikan Karakter. Bandung: Refika

Anton, M. Mulyono. 2001. Aktivitas Belajar. Bandung: Yrama

As'Adah S.N , Made Sutama, Gede Nurjaya. (2016). "Pembelajaran Menulis Teks Prosedur Berdasarkan Hasil Wawancara di Kelas VIII A1 SMP Negeri 1 Singaraja. Jurnal Jurusan Pendidikan Bahasa dan Sastra Indonesia Vol 5 No 3 (di unduh 15 Nov 2019)

Hamalik, Oemar. (2001). Proses Belajar Mengajar. Jakarta : Bumi Aksara.

Harsiati, T. Trianto, A. \& Kosasih, E. 2017. Bahasa Indonesia SMP/MTs Kelas VII Edisi Revisi 2017. Jakarta: Kementerian Pendidikan dan Kebudayaan.

Kemendikbud. 2013. Informasi Kurikulum 2013. Jakarta: Depdikbud.

Nasution, S. (2000). Berbagai Pendekatan Dalam Proses Belajar Mengajar. Jakarta: Bumi Aksara.

Pradana, Putu Gede Ari, dkk. 2015. Pembelajaran Menulis Teks Prosedur dengan Metode Discovery Learning di Kelas X MIA A SMA Negeri 1 Blahbatuh, e Journal Jurusan Pendidikan Bahasa dan Sastra Indonesia, Undiksha, Vol. 3, No. 1.

Priyatni, Endah Tri. 2014. Desain Pembelajaran Bahasa Indonesia dalam Kurikulum 2013. Jakarta: Bumi Aksara.

Ratumanan. (2015). Inovasi Pembelajaran. Yogyakarta: Penerbit Ombak.

Roestiyah N.K. 2008. Strategi Belajar Mengajar. Jakarta: Rineka Cipta.

Slameto. 2010. Belajar dan faktor-faktor yang Mempengaruhinya. Jakarta: PT. Rineka Cipta

Sriyono. 2008. Aktivitas dan Prestasi Belajar. http://ipotes.wordpress.com/2008/

Tarigan, Henry Guntur. 2008. Membaca Sebagai Suatu Keterampilan Berbahasa. Bandung: Angkasa.

Winataputra,US.,dkk. 1995. Belajar dan Pembelajaran. Jakarta: Depdikbud. 